Lobo Guerrero Arenas, J. (2019). Patrimonio sin dolientes: valor y uso del patrimonio. El caso del Museo Cultural de Arte Religioso de Mompox. Revista de Antropología y Sociología: VIRAJES, 21(2), 185-203. DOI: 10.17151/rasv.2019.21.2.9

\title{
Patrimonio sin dolientes: valor y uso del patrimonio. El caso del Museo Cultural de Arte Religioso de Mompox*
}

\author{
JIMENA LOBO GUERRERO ARENAS**
}

Recibido: 5 de marzo de 2019

Aprobado: 29 de abril de 2019

Artículo de investigación

\footnotetext{
* Este artículo constituye una versión revisada de la ponencia presentada en el Congreso Internacional Historia, Museos y Patrimonio, Santa Marta, noviembre de 2018.

** Doctora en Antropología y Arqueología. Docente del Departamento de Antropología y Sociología de la Universidad de Caldas. E-mail: jimena.loboguerrero@ucaldas.edu.co. (1) ORCID: 0000-0003-4996-7805. Google Scholar
} 


\title{
Resumen
}

Este artículo se deriva de un trabajo de investigación más amplio realizado en Santa Cruz de Mompox entre 2012 y 2014. Entrevistas no estructuradas, observación directa en campo y el trabajo con la colección del Museo Cultural de Arte Religioso de Mompox sirvieron de insumo para reflexionar sobre el patrimonio cultural alrededor de preguntas como: ¿qué y por qué se patrimonializa? La propuesta museográfica pretende mostrar al visitante el esplendor y riqueza de la tradición orfebre momposina, tradición que constituye uno de los referentes patrimoniales de la ciudad. Sin embargo, los resultados del trabajo de campo dejan ver que la colección carece de dolientes. Reflexionando desde los estudios críticos del patrimonio, se concluye que el descuido, invisibilización y olvido de la colección devela lo problemático de los ejercicios selectivos de patrimonialización e invita a cuestionar los usos y el valor que se suelen otorgar al patrimonio.

Palabras clave: Patrimonio, Mompox, museos, patrimonialización, bienes culturales.

\section{Heritage without the bereaved: value and use of heritage. The case of the Cultural Religious Art Museum of Mompox}

\begin{abstract}
This article is derived from a larger research work carried out in Santa Cruz de Mompox between 2012 and 2014. Unstructured interviews, direct observation and work with the collection of the Cultural Religious Art Museum, served as input to reflect on cultural heritage around questions such as: What and why is it patrimonalized? The museographic proposal aims to show visitors the splendour and richness of the Momposino goldsmith tradition, a tradition that constitutes one of the city's heritage references. However, results show that the collection lacks the bereaved. Reflecting from the critical studies of heritage, it is concluded that the neglect, invisibility, and forgetfulness of the collection reveals the problem of the selective exercises of patrimonialization and invites to examine the uses and the value that are usually given to cultural heritage.
\end{abstract}

Key words: heritage, Mompox, museums, patrimonialization, cultural goods. 


\section{Introducción}

orillas del Río Grande de la Magdalena, al sur del
departamento de Bolívar, enclavada en medio de la Depresión
Momposina, se erige Santa Cruz de Mompox, población fundada en 1534 por Alonso de Heredia en territorio ocupado en época anterior a la conquista española por grupos indígenas de origen Malibú de quienes cada vez se sabe un poco más ${ }^{1}$, pero a quienes por lo general poco o nada se les recuerda cuando de temas patrimoniales se trata. Ha sido, por el contrario, su imponente arquitectura colonial la que en 1995 le sirvió para procurarse el título de Patrimonio Mundial de la Humanidad otorgado por UNESCO${ }^{2}$. No obstante, sin demeritar el indiscutible valor patrimonial que tiene dicho conjunto arquitectónico, existen en Mompox algunos otros patrimonios, menos visibles, que no constituyen puntos de referencia y no han sido objeto de procesos de patrimonialización ${ }^{3}$ como el del conjunto arquitectónico mencionado.

Hoy en día, la Casa Bolivariana, mejor conocida como Museo Cultural de Arte Religioso, alberga alrededor de 160 objetos de oro, plata y piedras preciosas declarados bienes de interés cultural (BIC) $)^{4}$. Sin embargo, la precaria puesta en escena de un montaje museográfico que ni siquiera logra aislar a los objetos del polvo y las pestes, deja claro que lo patrimonial no es una categoría que opera aislada de las dinámicas sociales locales y que no sirve necesariamente de escudo de protección y salvaguarda como normalmente suele pensarse. El uso y valor que se da al patrimonio, en el sentido que García-Canclini (1999) otorga a estas dos acepciones, dependen de variables que normalmente ponen en evidencia la dispar normativa y el conflicto de intereses que se suscitan entre los marcos jurídicos y los participantes que promueven los procesos de patrimonialización, así como los diferentes intereses tanto políticos como económicos que dichos procesos conllevan. El conjunto de bienes de interés cultural que se exhiben en el Museo Cultural de Arte Religioso en Mompox pretende mostrar al

\footnotetext{
${ }^{1}$ Ver por ejemplo el trabajo de grado en Antropología de Julián Castañeda en 2016 y los informes de trabajo de campo del arqueólogo Luis Choperena Tous en 2012.

${ }^{2}$ Santa Cruz de Mompox ha sido declarada también Pueblo Patrimonio de Colombia, Bien de Interés Cultural de la Nación (Monumento Nacional) y Distrito Especial Turístico Cultural e Histórico de Colombia.

${ }^{3}$ En este texto la palabra patrimonialización será entendida como el conjunto de acciones de inventario, registro, gestión y preservación de las diversas manifestaciones tanto culturales como naturales, materiales como inmateriales, conducentes a que dichas manifestaciones se eleven a la categoría de patrimonio, es decir, se activen como bienes patrimoniales.

${ }^{4}$ Siguiendo a Prott y O'Keefe (1992) el término patrimonio cultural es más amplio que el de bien de interés cultural y no se refiere a cuestiones jurídicas mientras este último sí lo hace.
} 
visitante el esplendor del pasado y la riqueza de una tradición orfebre que, curiosamente, hoy por hoy, junto a su arquitectura de carácter colonial, también constituye uno de los referentes patrimoniales y turísticos de la valerosa villa, término este último por el que comúnmente se conoce a Mompox. Sin embargo, desde hace más de 20 años, la colección carece de dolientes. La invisibilización y por ende el olvido en el que ha caído nos invita a reflexionar sobre los usos y el valor del patrimonio cultural.

Durante la segunda temporada de campo de una investigación más extensa realizada entre 2012 y 2014, referente al trabajo del oro y la plata en Santa Cruz de Mompox (Lobo Guerrero 2014), a lo largo de dos meses y medio se llevaron a cabo entrevistas de carácter abierto a varias de las personas que de una u otra manera están relacionadas con el trabajo en el museo, así como también a visitantes tanto nacionales como extranjeros. De igual manera, el trabajo con la colección permitió conocer de cerca los pormenores con respecto al estado de conservación de las piezas (Lobo Guerrero y Galarza 2013). Los datos recuperados en las entrevistas, así como el trabajo directo con los objetos de oro y plata y la elaboración de un diagnóstico preliminar sobre su estado de conservación, sirvieron de insumos para aproximarnos a la idea de patrimonio, lo patrimonial, la conservación y preservación del patrimonio mueble en Mompox. Derivado del trabajo de campo descrito, pero también a la luz de investigaciones recientes alrededor de los estudios críticos del patrimonio, me pregunto en este texto: ¿Qué se patrimonializa y por qué?, ¿qué valor y qué usos se otorgan al patrimonio y quiénes los otorgan y por qué? En últimas, ¿cuál es el proceso por medio del cual las sociedades contemporáneas otorgan al pasado un lugar dentro de sus dinámicas de preservación y conservación?, es decir, ¿depende el patrimonio, su conservación y perpetuidad en el tiempo, de la relación directa que pueda existir entre el bien cultural y el grupo de personas o comunidad que vela y responde por él? (Harrison, 2015, p. 37).

Ciertamente las preguntas anteriores no resultan novedosas, puesto que básicamente hacen parte del pool de preguntas obligadas cuando pensamos de manera crítica frente a este asunto de lo patrimonial, sin embargo, invitan a la reflexión, propósito central de este escrito.

\section{La legalidad de una tradición orfebre en el olvido}

En 1959, Mompox fue declarada Monumento Nacional y en 1995 Patrimonio Mundial de la UNESCO, "como una muestra depurada de la arquitectura colonial española en el Nuevo Mundo" (UNESCO, 2003). Forma parte de dicho conjunto arquitectónico la casa del siglo XVIII ubicada sobre la calle Real del Medio que perteneció a la familia Gutiérrez de 
Piñeres y que fue adquirida en 1982 por la sociedad Hostal Doña Manuela, compuesta en aquel entonces por el Ministerio de Desarrollo Económico y el municipio de Mompox. Poco tiempo después dicha sociedad fue liquidada y la casa entregada a Mompox como su parte en esta sociedad. En 1990, el gobierno nacional presidido por el expresidente Virgilio Barco Vargas apoyó el interés de la comunidad momposina de crear un museo de arte religioso en el que serían depositadas las alhajas que por tradición centenaria conservaban distinguidas familias de la ciudad, así como diferentes parroquias y cofradías. En dicho año, la casa en cuestión, conocida popularmente como Casa Bolivariana, puesto que allí se hospedó el libertador en su paso por la valerosa villa, se destinó para la creación del Museo Cultural de Arte Religioso y gracias a fondos aportados por el Banco de la República, la Corporación Nacional de Turismo y Colcultura, en uno de sus cuartos se construyó una bóveda de seguridad para depositar las alhajas. En paralelo, se realizó la concesión en comodato del inmueble y se conformó la Fundación Cultural de Mompox, ente que desde entonces se ha encargado de la custodia de la colección y del manejo de la casa y del museo. Desde 1990, esta fundación se reconoce como institución sin ánimo de lucro mediante personería jurídica otorgada por la Gobernación de Bolívar y registrada en la Cámara de Comercio de Magangué, siendo su principal función la de administrar y dirigir el Museo Cultural de Arte Religioso de Mompox.

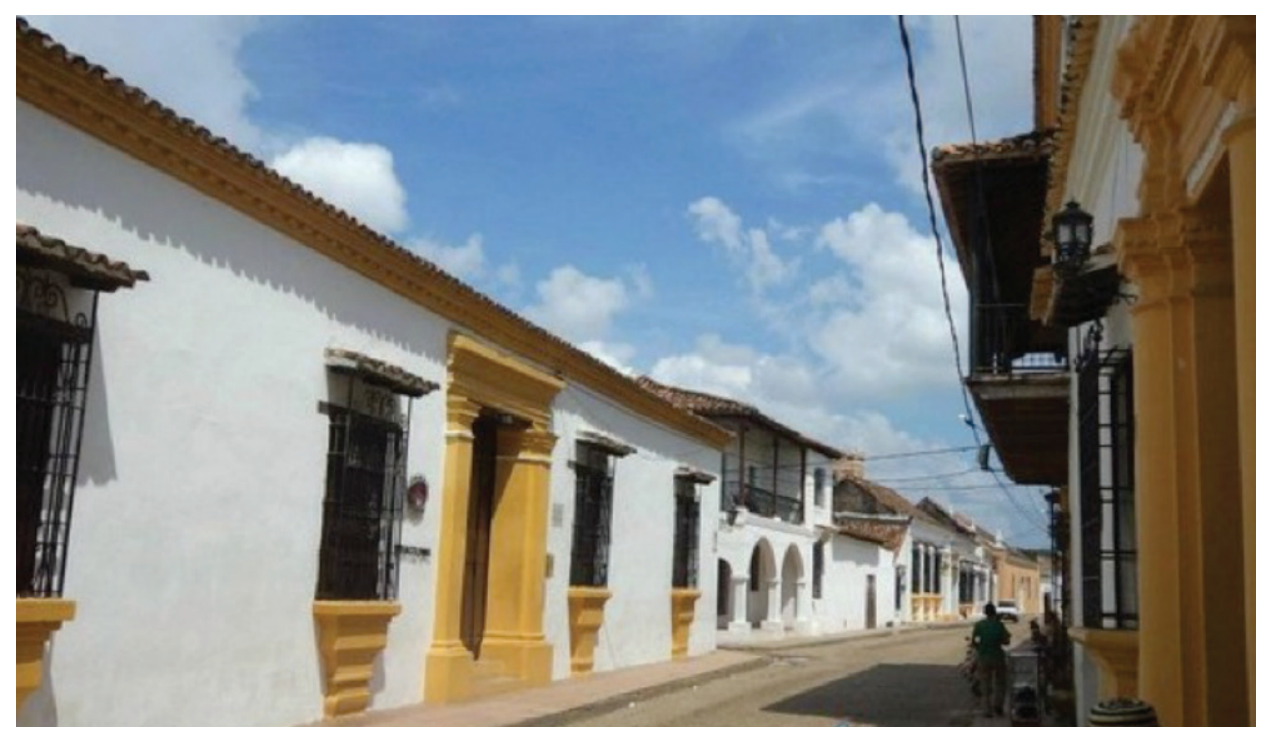

Imagen 1. Calle Real del Medio. A la izquierda (portada amarilla), Museo Cultural de Arte Religioso. Fotografía de la autora. 
Al poco tiempo de creado el museo, en 1996, la colección fue declarada Bien de Interés Cultural, BIC de la nación ${ }^{5}$. Un BIC en Colombia es un bien material mueble o inmueble al que se le atribuye un especial interés histórico, artístico, científico, estético o simbólico en diversos ámbitos como el plástico, arquitectónico, urbano, arqueológico, lingüístico, sonoro, musical, audiovisual, fílmico, testimonial, documental, literario entre otros. Este tipo de declaratoria se encuentra reglamentada por la Ley 1185 de 2008 que modificó la Ley 397 de 1997 o Ley General de Cultura y que corresponde a su vez a la Ley para la protección del Patrimonio Cultural de la Nación. ${ }^{6}$ Se considera patrimonio de la Nación a:

todos los bienes materiales, las manifestaciones inmateriales, los productos y las representaciones de la cultura que son expresión de la nacionalidad colombiana, tales como la lengua castellana, las lenguas y dialectos de las comunidades indígenas, negras y creoles, la tradición, el conocimiento ancestral, el paisaje cultural, las costumbres y los hábitos, así como los bienes materiales de naturaleza mueble e inmueble a los que se les atribuye, entre otros, especial interés histórico, artístico, científico, estético o simbólico en ámbitos como el plástico, arquitectónico, urbano, arqueológico, lingüístico, sonoro, musical, audiovisual, fílmico, testimonial, documental, literario, bibliográfico museológico o antropológico. (Ministerio de Cultura. Ley 1185 de 2008. Artículo 4to.)

Dos aspectos son claros hasta este momento. El primero, que cuando nos referimos a la colección de arte sacro del Museo Cultural de Arte Religioso de Mompox estamos hablando de bienes de interés cultural, es decir, objetos que en su momento fueron reconocidos por el gobierno nacional como de interés histórico, artístico o estético. El segundo, que existe un ente administrativo, la Fundación Cultural de Mompox, que custodia la colección, organismo por lo demás compuesto por momposinos, algunos de ellos custodios por herencia directa de las alhajas que conforman la colección. De lo anterior se podría deducir entonces que existen al menos tres dolientes directos de los bienes culturales en cuestión. Por un lado el Estado, quien mediante la emisión de un decreto decidió que este grupo de objetos debía formar parte del patrimonio cultural de la nación. Por el otro,

\footnotetext{
${ }^{5}$ Decreto 2008 del 5 de noviembre de 1996. Colección de obra mueble de la Fundación para la Conservación del Patrimonio Religioso de Mompox. A 22 de marzo de 2018 el Ministerio de Cultura contaba con 1106 bienes entre muebles e inmuebles, declarados Bien de Interés Cultural BIC.

${ }^{6}$ Es importante llamar la atención sobre la coincidencia que existe entre la definición de bien de interés cultural y la de patrimonio. Ambos conceptos se refieren al mismo tipo de bienes materiales.
} 
la comunidad, vecinos de Mompox quienes en su momento se reúnen y deciden apadrinar una colección. Y, en tercer lugar, la fundación, entidad sin ánimo de lucro, quien a través del museo custodia la colección y constituye a su vez el espacio contenedor de la misma. Así las cosas, se esperaría que la colección se encontrara en óptimas condiciones, que su puesta en escena fuese también la adecuada, que tuviese la visibilidad y dinamismo del que normalmente gozan colecciones de arte sacro tan importantes como ésta y que estuviese además en excelente estado de conservación; en últimas, que las normas y regulaciones existentes con respecto a bienes patrimoniales se aplicaran eficazmente. Sin embargo, la realidad es otra. La existente desarticulación entre museo, fundación, comunidad y legislación se refleja de manera notable en la precaria situación en la que se encuentra la colección hoy día. De cierta forma, en el sentido en el que lo expresan Bennett et al. (2017), no ha existido interconexión en las dinámicas que tienen que ver con los procesos de coleccionar, ordenar y gobernar estos objetos patrimoniales; o, dicho de otra manera, es evidente la escasa relación que existe entre "las instituciones que rigen las políticas culturales, los intermediarios y las comunidades que se plantean como sus beneficiarias" (Chaves, Montenegro y Zambrano, 2010, p. 7).

\section{Entendiendo las dinámicas del patrimonio cultural: El caso del Museo Cultural de Arte Religioso de Santa Cruz de Mompox}

Son las 9 de la mañana y junto a otro par de visitantes, frente a la puerta de entrada a la Casa Bolivariana, espero a la persona encargada de abrir el museo. Son casi las 10 a.m. y la espera continúa. Haciendo eco a la idea que aún pervive en el imaginario de los colombianos cuando nos referimos a las tierras bajas del Caribe, aquellas en las que el tiempo se detiene, el tiempo no pasa o el tiempo cada uno lo maneja a su acomodo (Le Goff, 1991), esa persona finalmente aparece y abre la puerta del museo. Se trata de una típica casona colonial. Un zaguán amplio y tapizado por cantos rodados nos recibe, mientras un largo patio que se extiende paralelo a la Calle Real del Medio invita a revivir imágenes de un glorioso pasado. Los cuartos se distribuyen alrededor del patio y una reja en hierro forjado nos recuerda que la tradición metalúrgica propia de esta villa permea cada rincón; la reja enmarca, pero a la vez divide el área donde reposa la exposición. La precaria condición del inmueble es evidente, sin embargo, es poco el tiempo que transcurre entre esa primera impresión y el llamado de atención que nos hace para escuchar juiciosamente las reglas a seguir dentro del museo. Se dirige entonces a nosotros para impartir instrucciones con respecto al uso de cámaras fotográficas y el consumo de alimentos. Finalmente, toma 
asiento en una mecedora tejida con la tradicional estera momposina, otro de los acervos patrimoniales de la ciudad, estratégicamente localizada a la entrada del área de exhibición desde donde, de ahora en adelante y hasta las 12 del día, le dará la bienvenida a los visitantes, al tiempo que seguirá atentamente la programación de la televisión nacional acompañada por su dedicada labor de costura en punto de cruz y un patrullero de la policía nacional que hace las veces de guardia de seguridad pero también de guía turístico. Han transcurrido menos de tres cuartos de hora y hemos terminado de recorrer las primeras dos salas, es hora de pasar a la bóveda. Nuestra anfitriona se dirige ahora hacia la puerta en donde nos facilitará el acceso, ella es, nuevamente, la encargada de abrir la puerta; debe retirar un par de candados. Una vez dentro del recinto, la primera impresión no es alentadora y la siguiente lo es menos.

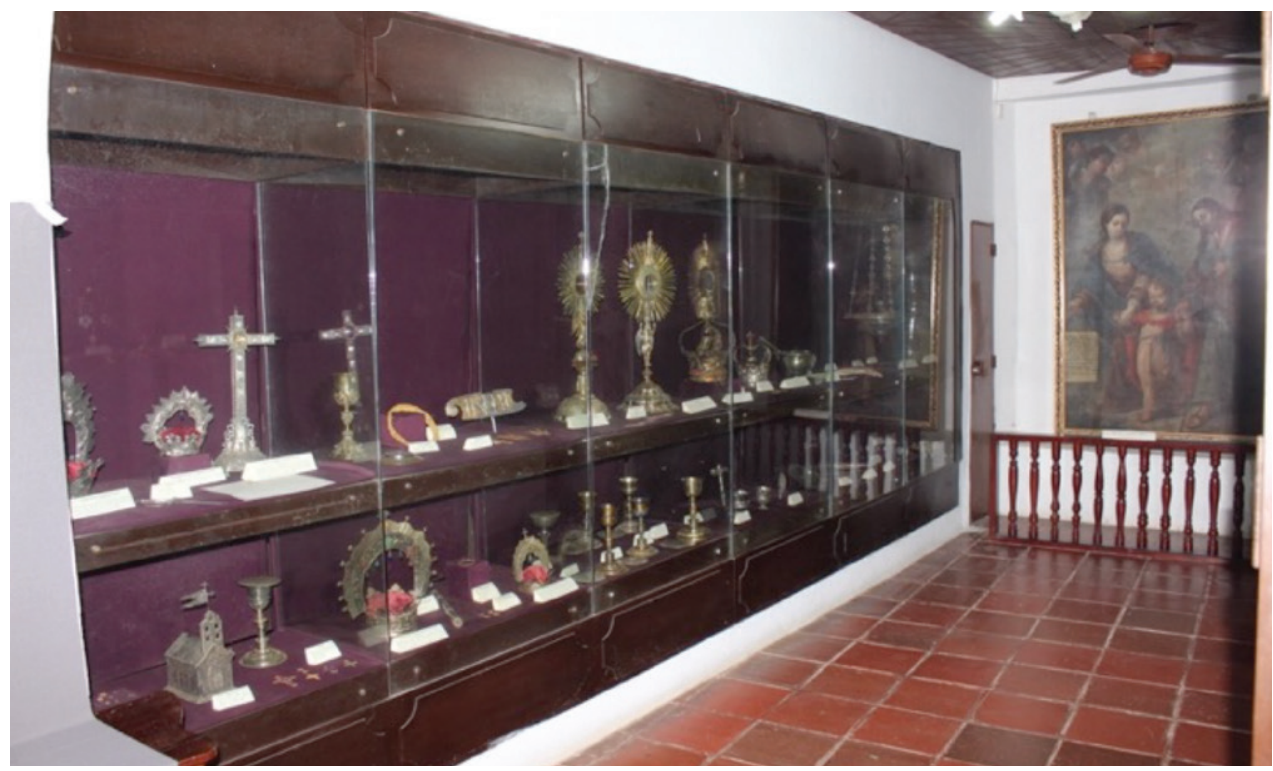

Imagen 2. Vitrina principal dispuesta de pared a pared dentro de la bóveda del Museo de Arte Religioso. Fotografía de la autora.

El espacio en el cual fueron depositadas las alhajas en 1990 luce tal cual las fotos el día de su inauguración. La desatención es más que evidente. La puesta en escena del montaje museográfico no se corresponde en lo absoluto con lo que la ley dicta en cuanto a normativas de conservación y preservación del patrimonio mueble ni tampoco con las políticas de atención al patrimonio con las que normalmente operan -o deberían en teoría operar- 
hoy día los museos en cualquier parte del planeta. No existe ningún tipo de protocolo que garantice la preservación de las piezas, ni mucho menos su seguridad. Cada año, por ejemplo, la comunidad momposina, a través de la Corporación Autónoma de Semana Santa (Corposanta), solicitaba en préstamo a la Fundación la Corona de la Virgen dela Dolorosa ${ }^{7}$. Dicha corona normalmente ocupa un lugar principal dentro de una de las tres vitrinas de la bóveda del museo. Durante la Semana Mayor se removía, y pasaba a formar parte del ajuar que luce la Virgen de la Dolorosa que en andas recorría las calles de la ciudad en los desfiles procesionales. Claramente, la corporación se preocupaba por la integridad de la pieza al cubrir el paso con un techo falso que en algo la protegía, sin embargo, era evidente el riesgo que corría. Típicamente y desde el campo de la conservación de bienes muebles priman los principios de mínima afectación para asegurar la conservación a futuro de los objetos. En este sentido, varios movimientos, traslados, exposición al medio ambiente y manipulación afectan una corona como la de la Dolorosa e inciden eventualmente en su deterioro, convirtiéndola por tanto en un bien vulnerable.

Las miradas entre los visitantes son de asombro, extrañeza y desconcierto. La colección es única al tiempo que lo es su estado de conservación. Las tres vitrinas que componen esta sala se recorren rápidamente, no sólo porque las dimensiones son reducidas sino porque es poca la información que se proporciona al visitante. La cédula de cada objeto, dispuesta por lo general al pie de este, suele suscitar duda en lugar de aclaración. La visita termina pronto.

\begin{abstract}
$\mathrm{Al}$ museo acuden a diario turistas tanto nacionales como extranjeros, así como grupos de estudiantes de colegios de Mompox y municipios aledaños. Los indicadores señalan un número aproximado de 8000 visitas al año que permanentemente se quejan de las precarias condiciones, tanto de las piezas como de la forma en que están expuestas al público ${ }^{8}$. Basta con repasar rápidamente las páginas de viajeros en internet para encontrar frases como "el museo es pequeño no tiene mucho para ver, y la instrucción del guía no es de mayor interés, muy superficial, en el lugar no se puede acceder con cámaras por la seguridad de las joyas religiosas, está sobrevalorado". Algunos de los títulos que encabezan los comentarios de viajeros en la página de Tripadvisor, una de las web más reconocidas por viajeros en el mundo, son: "Un museo olvidado", "Pobremente ambientado", "Flojo", "Mal servicio", “Hermosos objetos, no bien presentado".
\end{abstract}

\footnotetext{
${ }^{7}$ Esta práctica dejó de llevarse a cabo en 2012.

${ }^{8}$ Comunicación personal, Fundación Cultural de Mompox.
} 
Las dinámicas del patrimonio cultural suelen ser diversas. En el caso del Museo Cultural de Arte Religioso de Mompox pueden ser, leerse al menos, desde dos perspectivas. Para la fundación, es decir, 'de puertas para adentro', resulta más que evidente la necesidad de renovación del guion museográfico y pese a que es prioritario recaudar fondos para emprender acciones que garanticen la seguridad, mantenimiento y adecuada exhibición de la colección, son prácticamente inexistentes las iniciativas encaminadas a buscar los recursos para llevar a cabo estas tareas 9 .

Algo muy diferente sucede con el inmueble. Lo arquitectónico, ese 'de puertas para afuera', es lo que patrimonialmente cobra importancia. La restauración arquitectónica de la Casa Bolivariana ha sido ya varias veces formulada y presentada ante las entidades del gobierno local; el último intento bajo el título "Proyecto de Mantenimiento Casa Bolivariana - Museo Cultural de Arte Religioso" estuvo dirigido al Banco Municipal de Programas y Proyectos de Inversión Municipal (BPINM). Dicho proyecto fue incluido dentro del Plan de Desarrollo Municipal 2016-2019 "Mompox sí avanza, Mompox competitivo" proyecto que a su vez se encontraba alineado con el Plan de Desarrollo Departamental 2016-2020 "Bolívar Sí Avanza con Cultura para la Paz", en el cual uno de sus objetivos estaba dirigido a "fortalecer los diferentes escenarios culturales del departamento de Bolívar como espacios para la generación de contenidos culturales y la interacción ciudadana a través del arte y la cultura" (Gobernación de Bolívar, 2017, p. 404). En suma, frente a las pocas, pero al menos existentes, intenciones por preservar y restaurar el inmueble, no existe a la fecha un proyecto que se encargue de velar directamente por la colección de arte sacro que alberga el museo, su restauración, conservación, gestión y puesta en valor ${ }^{10}$.

La colección constituye un bien cultural y por tanto desde el punto de vista jurídico se encuentra regulada y amparada por las leyes de patrimonio cultural colombianas. No obstante, sucede que en buena parte tanto los estudios como las intervenciones a bienes patrimoniales en Colombia han estado dirigidas tradicionalmente a la preservación del patrimonio cultural inmueble y arqueológico

\footnotetext{
${ }^{9}$ La autora de este artículo ha presentado al Ministerio de Cultura y al Banco de la República proyectos encaminados a la restauración/conservación de las piezas y renovación museográfica de la sala. Lastimosamente, las propuestas no han sido favorecidas.

${ }^{10}$ La autora del presente escrito formuló en 2016 el proyecto titulado "Proyecto integral para la restauración y conservación de la colección de orfebrería y renovación museográfica del Museo de Arte Religioso de Santa Cruz de Mompox" en el marco de la Convocatoria para la conservación y restauración del patrimonio cultural colombiano, Banco de la Republica. La propuesta no fue favorecida.
} 
(Chaves et al, 2010, p. 8). Ejemplo de lo anterior lo encontramos en Mompox mismo, cuando en 2014 el presidente Santos inauguró 2,7 km (un área de $180.000 \mathrm{~m}^{2}$ ) correspondientes al segundo de tres tramos que forman parte del proyecto de restauración formulado por el plan especial de manejo y protección del centro histórico, PEMP 2007 y el programa de recuperación de centros históricos del Ministerio de Cultura, proyecto que buscó revitalizar el eje urbano de la Albarrada de Mompox. Con una inversión de $\$ 21.790$ millones de pesos éste fue en Colombia, "una de las inversiones más importantes que se han hecho para la recuperación de un centro histórico" (Garcés, 2014). De manera anecdótica, menos del $1 \%$ de esta inversión es la que se requeriría para llevar a cabo la renovación museográfica de la totalidad del museo.

Las fachadas de las casas, las plazas y las calles del centro histórico de Mompox forman parte del patrimonio que se exhibe, que se muestra, visible, un patrimonio 'de puertas para afuera', cuyo uso y valor juegan un papel importante en la economía del municipio. Tal y como lo expresa Harrison (2015), en el mundo moderno las diferentes perspectivas acerca de lo patrimonial, la forma en que se muestra y se proyecta hacia el futuro -y en el presente también-, constituyen la representación de distintas realidades (p. 38). En este caso, la preservación del patrimonio cultural se convierte en excusa para el desarrollo de planes de inversión gigantescos como el anteriormente señalado, planes que conducen en el corto y mediano plazo a la generación de beneficios económicos de diversa índole para la comunidad. Esta relación entre lo patrimonial y su mercantilización ha sido ampliamente discutida en otros espacios (ej. Prats, 2006). Aquí, quisiera llamar la atención sobre la forma en cómo dicha relación logra opacar dinámicas patrimoniales que existen y subsisten más allá de las que son más visibles y generan mayor rentabilidad. Estas últimas van en contra de la puesta en valor de otros patrimonios singularmente menos visibles, cuya representatividad en términos económicos es también menor. Desde 2015, las calles y plazas de la ciudad se revisten de nuevos adoquines, bancos de descanso, parasoles y postes de luz. Se percibe al caminar un cierto aire de rejuvenecimiento. Aire que también se puede apreciar al entrar en casas en donde la inversión privada ha logrado transformar la ruina arquitectónica en acogedores hoteles tipo boutique. 


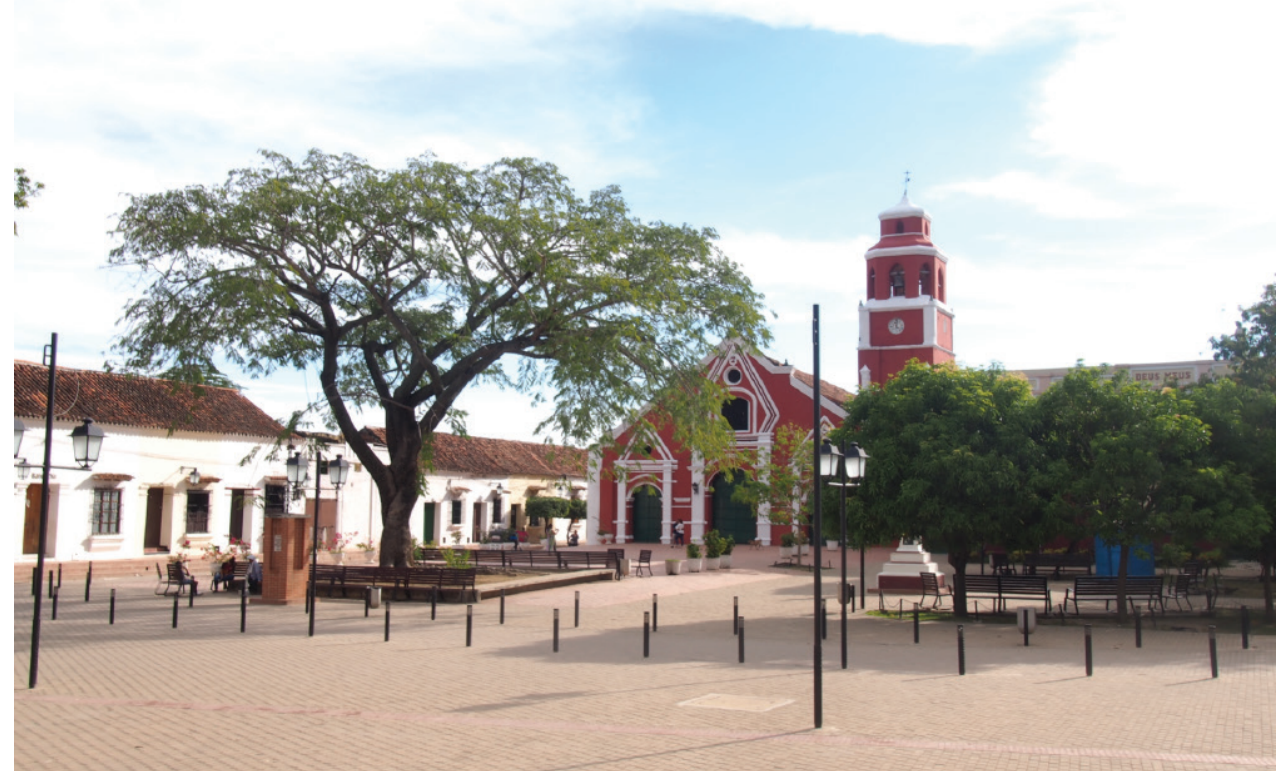

Imagen 4. Panorámica general de la Plaza de San Francisco después de las obras de restauración realizadas en 2015. Foto: https://creativecommons.org/licenses/by-sa/2.0/">(license) $</ a>$ )

Un conjunto de bienes patrimoniales como el que aquí discutimos, no forma parte ni de las intervenciones pasadas ni de los planes futuros de salvaguarda o protección de ninguna entidad gubernamental ni privada, puesto que aparentemente en poco o en nada contribuye y procura rendimiento monetario alguno ${ }^{11}$. Se trata de una dinámica bien conocida en nuestro presente en la que asistimos a la revitalización del patrimonio en función de intereses económicos que si bien cumplen con la norma, se alejan vertiginosamente de temas sensibles como la relación entre patrimonio, tradición e identidad.

Sin embargo, la dinámica anterior plantea una situación paradójica. Mompox se conoce, tanto nacional como internacionalmente por su tradición orfebre, en particular, por la elaboración de finos adornos de oro y plata que utilizan la técnica de la filigrana. Esta técnica, introducida por los españoles en algún momento durante el periodo colonial, a la cual se sumaron conocimientos de origen indígena y africano (Lobo Guerrero, 2016) constituye en sí misma un saber hacer tradicional que forma parte

\footnotetext{
${ }^{11}$ No obstante, existe la intención por parte de la alcaldía local, de participar con una propuesta para la revitalización del museo en la convocatoria de Estímulos 2019. Esta convocatoria hace parte de los planes de desarrollo propuestos por la "Economía Naranja" (Fuente: Comunicación personal señor Dimas Dau, Presidente Fundación Cultural de Mompox, junio de 2019).
} 
del conjunto de patrimonios con los que se asocia la identidad cultural del municipio. El Museo Cultural de Arte Religioso por su parte, como ya lo mencioné, alberga en su interior una cantidad importante de objetos elaborados en oro y plata, algunos de los cuales fueron fabricados en oro usando la técnica de la filigrana.

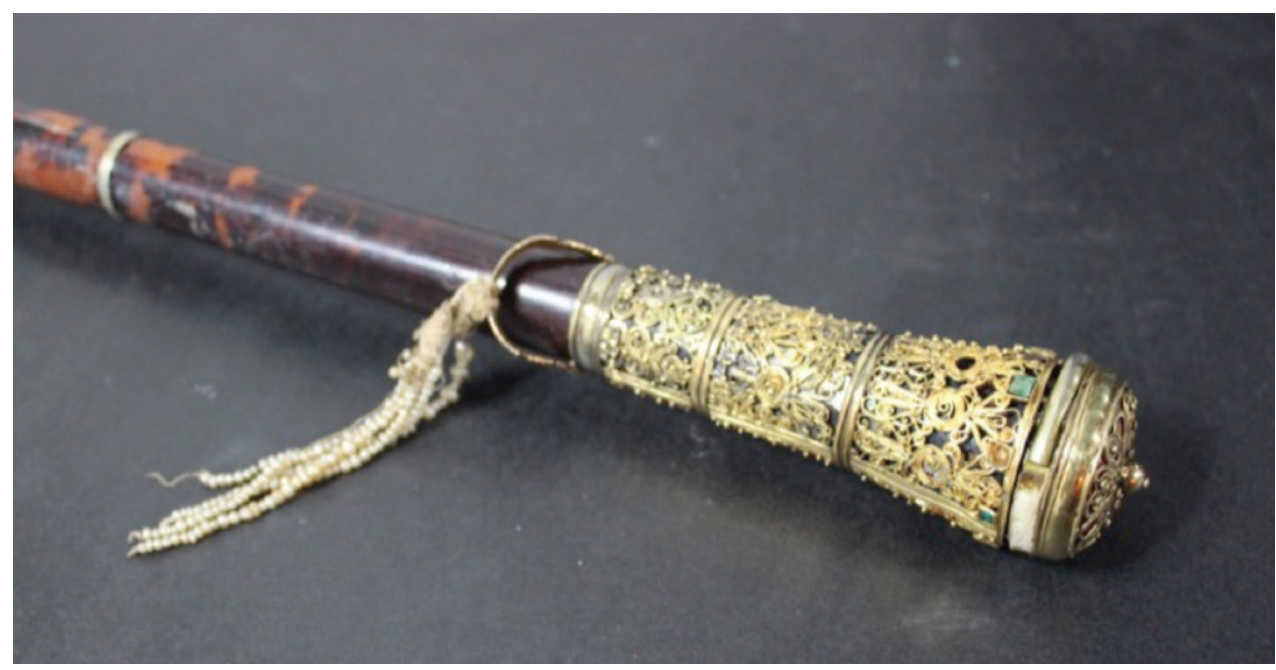

Imagen 5. Bastón ceremonial. Enchape en oro y piedras semipreciosas. Técnica filigrana. Fotografía de la autora.

Mompox es hoy día sinónimo de filigrana. Cientos de personas producen y comercializan 'el arte de la paciencia' (Peñas-Galindo, 1986); algunos incluso han traspasado fronteras y logran vender sus productos fuera del país. En Mompox, la filigrana, en tanto tradición orfebre, forma parte de la puesta en escena, 'de puertas para afuera', de lo patrimonial. Se trata de una tradición viva, presente, cercana al visitante, que se exhibe de maravillosas maneras en vitrinas que deslumbran por el brillo y color de cada pieza elaborada y que adquiere por lo demás un valor comercial importante. Caso contrario sucede con los objetos de oro y plata que reposan, 'de puertas para adentro', detrás de vidrios, unos añejos y otros rotos, en las vitrinas del museo. Se hace evidente en esta dinámica esa desigualdad estructural (García-Canclini, 1999), que se manifiesta en las contradicciones y tensiones que se suscitan en el uso que hace del patrimonio el Estado, el sector privado y la sociedad civil.

Ese aire de rejuvenecimiento que el Estado ha querido impregnar a la ciudad y que ha tenido eco en las otras múltiples apropiaciones de lo patrimonial por parte de la empresa privada y de la población local, no ha 
permeado las paredes de uno de los bienes inmuebles más destacados de la ciudad y mucho menos la materialidad de los invaluables objetos que alberga, pese a la intrincada conexión, casi ancestral, que ha existido entre el trabajo del orfebre, el mundo de los metales y la identidad del momposino. Es evidente que el grado de desatención de las directivas del museo, así como del gobierno tanto nacional como municipal y la comunidad momposina en general, no se corresponde con la importancia que reviste este conjunto declarado $\mathrm{BIC}$, ni con la afluencia de visitantes que tiene el único museo con que cuenta una de las dos ciudades declaradas patrimonio de la humanidad en Colombia, y que hoy ostenta uno de los mayores índices de afluencia anual de turistas tanto nacionales como extranjeros, ni mucho menos con la imbricada relación que existe entre la representación material de un arte que a todas luces connota cuestiones identitarias, que en últimas podrían leerse como una de las tantas dinámicas que adquiere el patrimonio cultural de un pueblo.

\section{Sobre el uso y el valor del patrimonio}

El tipo de preguntas que necesariamente siguen a la descripción de la situación anterior son: ¿a quién o quiénes importa o debería importar esta colección?, ¿quién o quiénes son en realidad sus dolientes?, ¿cuál es el valor que se le otorga?

Solemos acudir al término pasado para referirnos a situaciones pretéritas. En algunas ocasiones dichas situaciones reviven en el presente encarnadas en el mundo material. Cuando la operación anterior se suscita es porque se activa en nuestra mente un mecanismo de recordación mediante el cual individuos o colectivos son capaces de re-significar los objetos valiéndose de ordenamientos lógicos que tienen que ver con la forma en que se construye el pasado y se significa en términos de una materialidad específica -el objeto-, o lo que es lo mismo, lo que de ese pasado pervive o se activa en la memoria y que en el presente se convierte en lo patrimonial. Sucede lo anterior, por ejemplo cuando, al observar objetos contenidos en las vitrinas de los museos, activamos en nuestra memoria mecanismos que nos permiten vincular el objeto observado con narrativas atravesadas por temas como pasado, identificación, herencia, historia, pertenencia, tradición, cultura, representación, etc., temas todos relacionados con la definición de patrimonio. Por tanto, una dinámica como la anterior de recordación y re-significación de objetos que asociamos a lo patrimonial involucra entonces elementos relacionados con procesos en los que se configura y manifiesta algún grado de identidad (Arévalo, 2004; McDowell, 2008). Y es que patrimonio e identidad son dos conceptos 
que van de la mano y son relevantes para la construcción y legitimación del pasado tanto individual como colectivo (Prats, 1998; Graham y Howard, 2008).

Si entendemos los objetos patrimoniales como "aquellos productos culturales tangibles o intangibles que tienen un valor excepcional para una colectividad social determinada y que forman parte fundamental de su identidad cultural" (Bolfy, 2001, p. 82), convenimos en que tanto individuos como colectivos otorgan valor a dichos productos o bienes culturales cuando existe o se establece algún tipo de conexión o vínculo.

Pasa que en contextos como los del museo que aquí examino, los objetos detrás del vidrio no son reconocidos por la comunidad y no constituyen referentes materiales identitarios. Tan sólo cuando salen de ella, como en el caso de la corona de la virgen de la Dolorosa antes referido, cobran valor. Pese a que la asignación de valor resulta un ejercicio problemático que dependerá de múltiples circunstancias y puntos de vista, puesto que normalmente dicho ejercicio suele estar acompañado de una compleja serie de intereses económicos y políticos, en este último caso por ejemplo, vinculados a procesos de legitimación de poder (Ashworth, Graham y Tunbridge, 2007), aquí, sobre el conjunto de piezas de orfebrería pertenecientes a la colección del Museo Cultural de Arte Religioso de Mompox, los procesos de re-significación, apropiación y en últimas, de activación de dicho patrimonio se encuentran ausentes.

Los procesos de patrimonialización, o dicho de otra manera, la activación del patrimonio (Moncusí, 2005) resulta en últimas un complejo y conjunto heterogéneo de dinámicas sociales y culturales. Cada año somos testigos de no una, ni dos, sino varias declaratorias patrimoniales mundiales; la lista de patrimonio histórico cultural y natural de la humanidad va en aumento y como algunos autores ya lo han mencionado muchas veces, se cuestiona el sentido y la lógica tanto de la lista como de las razones para la aceptación o rechazo de las nominaciones (Frey y Steiner, 2011). Tal y como lo señala Prats (1998), el proceso de construcción del patrimonio posee un carácter ideológico, de representación y legitimación, y las activaciones de determinados referentes patrimoniales, están íntimamente vinculadas al poder político de los gobiernos de turno y a intereses comerciales de diversos frentes internacionales. Sólo que precisamente cuando dichos procesos de representación y legitimación dejan de existir o de ser relevantes para el grupo social, un conjunto de bienes culturales como el que compone la colección de objetos de arte sacro del Museo Cultural de Arte Religioso de Mompox deja de tener valor patrimonial. Dicho en otros términos si el proceso de patrimonialización implica la creación de un discurso sobre el pasado por parte de una comunidad en el presente 
(Frigolé, 2014), y depende además de la articulación de dicho discurso a cierto tipo de intereses tanto políticos como económicos, cuando priman otro tipo de intereses o éstos no coinciden con las políticas y las economías reinantes y los creadores de dicho discurso desaparecen, pareciera que con ellos desaparece también su valor patrimonial. A esto es a lo que yo llamo un patrimonio sin dolientes.

Y es que los ejercicios tanto de recordar como de olvidar, de visibilizar como de invisibilizar implícitos en los procesos de patrimonialización adquieren un papel determinante y una carga social importante. Es decir, inciden directamente en los procesos de activación de los bienes patrimoniales cuando éstos son seleccionados "del campo imaginario para pasar a formar parte de la realidad de una sociedad como patrimonio cultural" (Ramos, 2017). Es decir, cuando entran en el ámbito en donde se les atribuye un uso y se le reconoce un valor. Lograr que un bien, cultural o natural, sea declarado patrimonio significa reconocer su construcción social, la forma en que es apropiado, interpretado y visibilizado. Para ello resulta imprescindible su identificación y reconocimiento para conseguir su protección y conservación como herencia y legado para las futuras generaciones.

No cabe duda que, en gran parte debido a la declaratoria de 1995, el conjunto arquitectónico que constituye el centro histórico de la villa de Santa Cruz de Mompox, ha merecido y sigue mereciendo toda la atención del caso, debe ser tenido en cuenta, reconocido y valorado. Que su patrimonialización ha derivado en programas de desarrollo, en declaratorias, proyectos de restauración y conservación entre muchos otros. Pero, ¿en qué momento se decide, quién decide y con base en qué criterios que a la colección de arte sacro del Museo Cultural de Arte Religioso de Mompox no le corresponde atención alguna? ¿Qué tipo de valor o valoración se le está dando a este conjunto de bienes? ¿Para quién vale? Al indagar sobre estas preguntas desde la perspectiva de lo que sucede en la ciudad encontramos las posibles respuestas, por un lado, en la concepción que se tiene de lo patrimonial y en las variables empleadas para la activación de dicho patrimonio. Me refiero concretamente al reconocimiento de lo histórico y lo arquitectónico versus la invisibilidad de bienes culturales muebles que, pese a su reconocimiento nacional como bienes de interés cultural (BIC), no forman parte de la dinámica de lo patrimonial para los momposinos. Son estas dos variables, las visibles, las conocidas, las que han quedado inmersas en un 'de puertas para afuera', las que han servido para hablar de lo valioso. Ellas generan identidad, prestigio, fortalecen la identidad de un pueblo. Pero entonces, ¿qué pasa con lo que no se expone, con lo que el 
momposino no conoce; aquello que es lejano, que se encuentra fuera del alcance del público general, del momposino de a pie? Este es precisamente el caso de los objetos que forman parte de la colección del Museo Cultural de Arte Religioso de Mompox y la situación no deja de ser contradictoria.

La importancia que cobran los museos en la reivindicación de lo patrimonial, en los procesos de patrimonialización es de singular importancia. Los proyectos educativos, de proyección institucional, los ejercicios de sensibilización de los diferentes públicos que visitan un museo son herramientas fundamentales en los procesos de valoración del patrimonio, son éstos los encargados de poner en circulación el lenguaje patrimonial de puesta en valor, conservación, preservación, etc., al alcance del público general. Y es esto último lo que precisamente no sucede cuando nos enfrentamos a dinámicas en museos como el que aquí estamos examinando. Un nuevo guion museográfico representaría un mínimo paso para avanzar, un proyecto de trabajo conjunto entre museo y comunidad, de divulgación y apropiación de este patrimonio mueble, otro. Desafortunadamente, quien hoy día recorre la Casa Bolivariana y entra a la bóveda del museo no se lleva una buena impresión. Son prácticamente inexistentes las facilidades con las que cuenta el museo para ofrecer al visitante una experiencia lúdica interesante. Los objetos que componen la exhibición de la sala de orfebrería no cuentan ninguna historia y dejan en el visitante la sensación de abandono. Pareciera como si la definición de museo en tanto aquel lugar en el que confluyen diferentes objetos que conforman un discurso que representa en últimas una forma de valor cultural, se hubiese desdibujado y retrocedido en el tiempo para convertirse en ese espacio de almacenamiento, contemplación, una suerte de microcosmos estático y vacío (Lidchi, 1997, p. 160).

El patrimonio cultural es una categoría de clasificación de objetos socialmente construida, es decir que la patrimonialidad no proviene de las características intrínsecas de los objetos sino de las consideraciones e intereses que tengan los sujetos sobre estos (Tugores y Planas, 2006). En este sentido, hemos asistido aquí a un proceso de des-patrimonialización en la medida en que el valor que se le otorga a la colección que aquí nos ocupa ha desaparecido y su puesta en escena no conduce a fomentar procesos de reconocimiento ni de identificación. El patrimonio y los bienes patrimoniales se legitiman a partir de la institucionalización de las intenciones de conservación y preservación de la comunidad y cuando éstos dejan de existir, lo patrimonial de dicho patrimonio también se desvanece. 


\section{Una última reflexión}

Para terminar, quisiera resaltar dos cosas. Por un lado, la importancia de manejar hojas de ruta, de contar con objetivos específicos cuando se trata de ejecutar procesos de patrimonialización de lo cultural. Por el otro, el rol que juegan los museos en la visibilización de lo invisible. En la adecuada sensibilización y aproximación de lo que es y no es patrimonial al público general. Si bien es cierto que un bien cultural puede ser apreciado desde diferentes perspectivas y valorado de diferentes maneras, existe una evidente relación entre su uso y valor cuando éste, mediante su adecuada exhibición, adquiere un carácter visible y por ende es reconocido y apropiado por los individuos o los colectivos a quienes pertenece.

\section{Referencias bibliográficas}

Arévalo, J.M. (2004). La tradición, el patrimonio y la identidad. Revista de Estudios Extremeños, 60 (3), 925-956.

Arquez, O. y Peña, D.E. (1994). Espacio, poblamiento y sociedad en la región de Mompox. Medellín: Editorial Lealon.

Ashworth, G.T., Graham, B. y Tunbridge, J.E. (2007). Towards Pluralising Pasts: Theories and Concepts of Heritage. En Ashworth, G.T., Graham, B. y Tunbridge, J.E. (Eds.), Pluralising Pasts. Heritage, Identity and Place in Multicultural Societies (pp. 35-53). London: Pluto Press.

Bennet, T., Cameron, F., Dias, N., Dibley, B., Harrison, R., Jackins, I. \& McCarthy, C. (2017). Collecting, Ordering, Governing. Anthropology, Museums, and Liberal Government. Durham: Duke University Press.

Bolfy, C. (2001). Patrimonio cultural nacional: el marco jurídico y conceptual. Derecho y Cultura, 4, 79-107.

Castañeda, J.E. (2016). Rituales funerarios y alfarería. Municipio Los Palmitos, departamento de Sucre, Colombia. Una experiencia de arqueología y participación comunitaria (tesis de pregrado). Universidad de Antioquia. Medellín, Colombia.

Chaves, M., Montenegro, M. y Zambrano, M. (2010). Mercado, Consumo y Patrimonialización Cultural. Revista Colombiana de Antropología, 46 (1), 7-26. Recuperado de http://www. scielo.org.co/scielo.php?script=sci_arttext\&pid=S0486-65252010000100001\&lng=en\&tln $\mathrm{g}=\mathrm{es}$.

Choperena, L.C. (2012a). Arqueología de rescate en San Felipe, un lote urbano en Los Palmitos (Sucre). Alcaldía municipal de Los Palmitos. Informe ICANH. Bogotá (inédito).

Choperena, L.C. (2012b). Excavaciones arqueológicas en San Felipe, un cementerio indígena en Los Palmitos Sucre. Bogotá: Fundación de Investigaciones Arqueológicas Nacionales. FIAN (inédito).

García Canclini, N. (1999). Los usos sociales del Patrimonio Cultural. En: Aguilar

Criado, E. Cuadernos Patrimonio Etnológico. Nuevas perspectivas de Estudio. (pp. 16-33). Sevilla: Consejería de Cultura - Junta de Andalucía.

Frey, B.S. y Steiner, L. (2011). World Heritage List; does it make sense? International Journal of Cultural Policy, 17 (5), 555-573. 
Frigolé, J. (2014). La patrimonialización y mercantilización de lo auténtico. En Roigé, X., Frigolé, J. y del Mármol, C. (Coords.) Construyendo el patrimonio cultural y natural: Parques museos y patrimonio rural. (pp. 31-45). Valencia: Editorial Germania.

Garcés, M. (2014). Santos entrega obras en la Tierra de Dios. Recuperado de http://www. eluniversal.com.co/regional/bolivar/santos-entrega-obras-en-la-tierra-de-dios-173103

Gobernación de Bolívar (2017). Proyecto de ordenanza por medio del cual se adopta el Plan de Desarrollo para el Departamento de Bolívar, para el periodo constitucional 2016 -2019. Recuperado de http://www.funcicar.org/archivo/sites/default/files/archivos/ ordenanza_plan_final_.compressed_0.pdf

Graham, B. y Howard, P. (2008). Heritage and identity. In B. Graham \& P. Howard (eds.) The Ashgate Research Companion to Heritage and Identity. (pp. 1-15). Hampshire: Ashgate Publishing Limited.

Harrison, R. (2015). Beyond "Natural" and "Cultural" Heritage: Toward an Ontological Politics of Heritage in the Age of Anthropocene. Heritage \& Society, 8 (1), 24-42.

Le Goff, J. (1991). El orden de la memoria: el tiempo como imaginario. Barcelona: Paidós.

Lidchi, H. (1997). The poetics and the Politics of Exhibiting Other Cultures. En Hall, S. (ed.) Representation: Cultural Representation and Signifying practices. (pp. 151-222). London: Sage Publications \& Open University.

Lobo Guerrero, J. (2014). Changing Perspectives: The archives of memory and material culture. Archaeological Review from Cambridge, 29 (2), 69-87.

Lobo Guerrero, J. (2016). The Goldsmith's Workshop. A Study of Metallurgy during the Sixteenth and Seventeenth Centuries in Colombia (Tesis de Doctorado). University of Bristol. Bristol, Reino Unido.

Lobo Guerrero, J., y Galarza, F. (2013). Informe de trabajo. Diagnóstico y recomendaciones. Museo de Arte Religioso de Santa Cruz de Mompox. (inédito).

McDowell, S. (2008). Heritage, Memory and identity. En: Graham, B. y Howard, P. (eds.) The Ashgate Research Companion to Heritage and Identity (pp. 37-53) Hampshire: Ashgate Publishing Limited.

Ministerio de Cultura. Ley 1185 de 2008. Recuperado de http://www.secretariasenado.gov. co/senado/basedoc/ley_1185_2008.html

Moncusí, A. (2005). La activación patrimonial de la identidad. En Hernández Martí, G.M. et al., La memoria construida: Patrimonio cultural y modernidad. (pp. 91-121) Valencia: Tirant lo Blanch.

Peñas-Galindo, D.E. (1986). La orfebrería momposina: El aprendizaje de la paciencia. Boletín Cultural y Bibliográfico, 23 (7), 45-61.

Prats, Ll. (1998). El concepto de patrimonio cultural. Política y Sociedad, 27, 63-76

Prats, Ll. (2006). La mercantilización del patrimonio cultural: Entre la economía turística y las representaciones identitarias. Boletín del Instituto Andaluz del Patrimonio Histórico, 58, $72-80$.

Prott, L. y O'Keefe, P.O., (1992). Cultural heritage or cultural property? International Journal of Cultural Property, 1 (2), 3017-320.

Ramos, D. (2017). Sobre la construcción del patrimonio cultural y el proceso de patrimonialización. Mito. Revista Cultural 40. Recuperado de http://revistamito.com/laconstruccion-del-patrimonio-cultural-proceso-patrimonializacion/

Tripadvisor. Reviews Museo de Arte Religioso. Recuperado de https://www.tripadvisor. co/Attraction_Review-g445061-d6840467-Reviews-or10-Museo_Cultural_de_Arte_ Religioso_de_Mompox-Mompos_Bolivar_Department.html

Tugores, F. y Planas, R. (2006). Introducción al patrimonio cultural. Gijón: Ediciones Trea.

UNESCO. (1995). Mompox World Heritage Site. Recuperado de http://portal.unesco.org/es/ ev.phpURL_ID=12565\&URL_DO=DO_TOPIC\&URL_SECTION=201.html 